\title{
Assessing transport policies for tourist mobility based on accessibility indicators
}

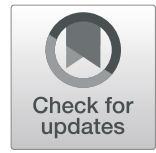

Pierluigi Coppola ${ }^{* *} \mathbb{D}$, Armando Carbone ${ }^{2}$, Carmine Aveta $^{2}$ and Piera Stangherlin ${ }^{2}$

\begin{abstract}
Tourism is a key sector in the national economies, representing a real asset for increasing the competitiveness and the world-wide visibility of a Country. In Italy, the widespread diffusion of the tourist heritage represents a great potential for the economic development but requires efforts to identify sustainable and seamless travel solutions, given the limited resources available for tourist mobility. The Italian National Plan of Tourist Mobility identifies in accessibility one of the key drivers for investment, and to this aim has developed a Planning Support System (PSS) to identify the investments to bridge up the accessibility gap of national tourist sites from the main airports, ports and railway stations (i.e. the "access gates" to the Country), either on the road network or using collective transport services. The PSS is based on the methodology presented in this paper, combining two concepts extensively studied in the literature, i.e. the generalized travel cost and the accessibility, in order to identify where and how to invest either to improve existing mobility services or to build new infrastructure. Given the number of tourist sites scattered over the national territory, the application of the proposed methodology to the Italian case study represents a relevant example of how accessibility measures can be applied in practice to link with policy goals and to identify planning priorities. The application is easily replicable and transferable at regional and local level.
\end{abstract}

Keywords: Tourism management, Accessibility measures usability, Planning support system, Infrastructure investments, Collective transport services

\section{Introduction}

Tourism is a key sector in Italy with an annual revenue of 171 billion Euro; it does contribute to the national GDP for about $12 \%$. With about 420 million of visitors per year [1] Italy is the third Country in Europe for tourist presences (after Spain and France) with a share of $13.4 \%$ on the total of EU28 Countries. Thanks to the international incoming, negative trends for tourist sector are rarely observed, not even during periods of recession. Moreover, the recovery from the recent economic crisis has been faster than in other economic sector (e.g. automotive, chemicals, banks, ...): in 2017 the number of incoming tourists has reached 56.8 million of visitors/year, with an increase of $38.6 \%$ with respect to year 2008 .

\footnotetext{
* Correspondence: pierluigi.coppola@polimi.it

'Polytechnic of Milan, Department of Mechanical Engineering, Via G. La Masa 1, 20156 Milan, Italy

Full list of author information is available at the end of the article
}

Given the strategic role of tourism in stimulating the national economy as well as in enhancing the image and the cultural heritage of the Country, a Strategic Plan for the Development of Tourism [2] has been launched in 2016, including a series of actions to support tourist areas, including rural and low-demand destinations. In fact, with its richness and variety of historical, cultural and natural sites, the Italian territory can offer a range of opportunities to meet multiple segments of tourist demand: from cultural to seaside attractions, from food and wine excellences to natural mountain landscapes. Seizing the opportunity of a vast supply of tourist attractions requires indeed to innovate the mobility services offered to guarantee proper level of accessibility compliant with the specific demand segments. Accessibility was indeed considered as a pre-requisite for the development of tourism, which in turn should represent an opportunity to improve life quality of residents and to avoid the population decline in remote areas. However, an ad hoc 
funding channel for the tourist mobility was not foreseen, at that time.

The National Plan of Tourist Mobility [3] following up the subsequent year, proposed a vision for the tourist sites as an interconnected system through integrated mobility services. This Plan represented the convergence point of two distinct institutional pathways, one within the Italian Ministry of Infrastructure and Transport for the strategic planning of transport and logistic infrastructure, it is called "Connecting Italy" [4], and the other one within the Italian Ministry of Cultural Heritage and Activities and of the Tourism, aiming at relaunching the strategic role of tourism [2]. Indeed the National Plan of Tourist Mobility represents the occasion for sharing the vision and the strategic objectives, and to fine tune the lines of intervention contained in the two strategic planning documents in order to optimize the use of resources for infrastructure and transport, also for the aims of tourist mobility.

Four specific objectives were identified in the Plan:

1. Accessibility, "Increase accessibility of tourist sites to boost the competitiveness of the tourist industry";

2. Digitization, "Digitize the tourist industry starting from mobility";

3. Infrastructure heritage, "Promote transport infrastructure as a form of tourist supply";

4. Sustainability, "Promote sustainable mobility for tourism".

Accessibility is considered as a key driver of the competitiveness of national tourist systems; it represents one of the most relevant variables for travelers' location choices, as it is proven that the more accessible a destination is, the more it is visited. The Plan aims at ensuring "physical" accessibility to all the tourist sites in order to decongest the major destinations and to exploit the whole cultural and tourist heritage, including minor sites and low-demand attractions, but also at promoting "digital" accessibility by means of advanced traveler information systems providing efficient, reliable and seamless travel solutions, to improve tourists' experience even before the travel starts.

Starting from a baseline where tourist trips using individual modes of transport (Car, Moto, Camper, ...) are more than $75 \%$ (Table 1), the Plan identifies as expected outcomes by year 2022, a reduction of tourist trips by car under $60 \%$, and an increase of public transport services for tourist purposes by $15 \%$ in the period 2017 2022. Moreover, maximum travel time to reach the main national tourist sites from the main airports, ports and railway stations is expected to be no longer than $1.5 \mathrm{~h}$.

Within the Plan, a Planning Support System (PSS) has been developed to bridge up the accessibility gap of
Table 1 distribution by transport mode of tourist trips in Italy

\begin{tabular}{lll}
\hline Transport mode & 2016 & 2017 \\
\hline Car & $76.7 \%$ & $73.5 \%$ \\
Bus & $4.6 \%$ & $6.4 \%$ \\
Camper, Auto-caravan & $2.4 \%$ & $2.1 \%$ \\
Moto, Moto-scooter, other & $1.7 \%$ & $1.1 \%$ \\
Total (road network modes) & $\mathbf{8 5 . 4 \%}$ & $\mathbf{8 3 . 1 \%}$ \\
Rail & $6.6 \%$ & $9.1 \%$ \\
Air & $5.1 \%$ & $6.2 \%$ \\
Maritime & $2.9 \%$ & $1.6 \%$ \\
Total (public transport services) & $\mathbf{1 4 . 6 \%}$ & $\mathbf{1 6 . 9 \%}$ \\
\hline
\end{tabular}

Source: our elaboration based on data by [1]

national tourist sites from the main airports, ports and railway stations (i.e. the "access gates" to the Country), either on the road network or using collective transport services. The PSS is based on a methodology combining two concepts extensively studied in the literature, i.e. the generalized travel cost and the accessibility. The aim is to identify where and how to invest either to improve existing mobility services or to build new infrastructure. In presenting the methodology and the application to the Italian case study, the paper intends to contribute to exploring the gap between theory and application, by seeking to understand to what extent integrated spatial and transportation modeling instruments do succeed in supporting decision-makers in planning practice. In fact, data availability and modeling complexity are considered as a barrier for the practical implementation of accessibility indicators. In this respect, the research gives an illustration of how a methodology that can be interpreted by decision-makers and directly linked to policy actions, can be suitable for actual planning purposes, even with some limitations from academic perspective.

The paper consists of five sections, including this introduction. Section 2 presents a literature review of studies focusing on tourist mobility and accessibility. Section 3 describes the proposed methodology to identify the accessibility gaps, including the travel cost functions and accessibility measures adopted. Section 4 discusses the results of the application of the proposed methodology to the Italian national case study, including the accessibility analysis for the above-mentioned tourist sites. Finally, in section 5 some conclusions are drawn.

\section{The usability of accessibility indicators in planning practice: literature review for tourist sector}

Many Planning Support Systems (PSS) have been developed aimed at measuring and modelling accessibility, however their implementation in planning practice remains an exception. The gap between the theory and the 
applications of accessibility tools for planning practice proves the need to maximize the usability of accessibility instruments and measures [5].

Hull et al. [6] observed that accessibility measures are in some cases too complex, abstract, hard to comprehend and to interpret, and that accessibility indicators, even though founded on strong methodological basis, must remain sufficiently simple and intuitively meaningful to be used by professional and Public Administrations in their application. Moreover, the link with policy goals is often weak and there are still many barriers to the implementation of such tools in planning practice [7], depending on the difficulties to communicate to end-users coming from several disciplines with different languages and areas of expertise (i.e. urban geographers, transport planners, and budgeting professionals) and, in some cases, with limited ability for using mathematical models.

In the attempt to develop a planning support system based on accessibility indicators for a sector that traditionally does not make extensive use of models (i.e. tourist investments management), the main difficulty is to maintain, at the same time, the technical rigor and the usability of the tool for practice, seeking for good balance between scientific rigor and practical relevance for the sector.

An unique definition for accessibility cannot be found in the literature, despite the concept of accessibility has been studied extensively in different disciplines such as transportation planning, geography, urban economics [8] and also in other sectors, such as regional development and growth [9] and agricultural production [10]. Originally Hansen [11] focused on the ease of fruition of a given service spatially separated from its beneficiaries and, accordingly, defined accessibility as "the potential of opportunities in the interaction". In fact, accessibility is often measured as the spatial impedances (time, cost, etc.) to the movement of people and the exchange of goods and services. However, the idea of considering the accessibility as a causal factor in transportation and location choice behavior came later (Burns, [12]). Nowadays, the accessibility has been widely used by transportation engineers and planners for modeling land-use and transport interactions (e.g. [13, 14]), for assessing transports plans or solving optimal location problems (see e.g. [15]).

Several taxonomies have been proposed in the literature $[8,16]$; here a classification based on whether the measures of accessibility do include or not behavioral components is proposed (Table 2). Accordingly, we distinguish two clusters of accessibility measures:

1) Behavioral (or individual-based) measures, defining accessibility from a single person/activity (subjective) perspective. They include:

a) the "utility-based" accessibility measures, derived from Random-Utility theory [17], according to which individuals aim at maximizing the net utility of participating in activities located in an area. They can be further classified into "activity-based" $[18,19]$ or "trip-based", depending on whether they take into account the daily activity schedule and the related trip chain respectively. More recently, Le Vine et al. [20] contributed to extent the definition of accessibility by incorporating the concepts of "Perceived Activity Set", defined as the set of out-of-home activities which they view as encompassing their potential travel needs when making decisions that structurally affect their accessibility (e.g. owning a car, a season public transport ticket).

b) the "contour measures", that define accessibility as the number of opportunities that can be accessed within a given distance or travel time, from a specific location in the study area (e.g. a station, an airport, etc.). These measures require the definition of the threshold of the maximum distance or travel time acceptable for individuals to reach the opportunities, which also vary with individuals' preferences, taste and habits. Hence, the more the opportunities are perceived heterogeneously by individuals, the less accurate the estimated accessibility values will result. To overcome such drawback, Cascetta et al. [21] have introduced the concept of "perceived opportunities" in the definition of this type of accessibility measures.

Table 2 Taxonomy of accessibility indicators

\begin{tabular}{|c|c|c|c|c|c|}
\hline Cluster & Accessibility measures & & Theoretical basis $^{\mathbf{a}}$ & Communicability $^{\mathbf{b}}$ & Operationalisation $^{c}$ \\
\hline \multirow{3}{*}{$\begin{array}{l}\text { Behavioral } \\
\text { (individual-based) }\end{array}$} & \multirow[t]{2}{*}{ Utility-Based measures } & Trip-based utility measures & + & - & - \\
\hline & & Activity-based utility/time-space measures & ++ & - & - \\
\hline & \multicolumn{2}{|c|}{ Contour measures/cumulative opportunities measures } & - & ++ & + \\
\hline \multirow{2}{*}{$\begin{array}{l}\text { Non Behavioral } \\
\text { (zone-based) }\end{array}$} & \multicolumn{2}{|l|}{ Network-based } & - & + & ++ \\
\hline & \multicolumn{2}{|l|}{ Gravity-based } & + & - & - \\
\hline
\end{tabular}

\footnotetext{
a Score: ++ strong theoretical basis; +moderately strong; - weak theoretical basis

b Score: +easy to communicate or interpret; + moderately difficult to communicate; - difficult

c Score: +easy to operationalize; + moderately difficult to operationalize; - difficult
} 
2) Non-Behavioral (or zone-based) measures, defining accessibility from a geographical impersonal perspective, based on potential opportunities spatially scattered among the zones of the study area. They include:

a) the "network-based" measures, founded on graph theory, that are based on the characterization of the topological properties of spatial networks; according to them, accessibility is directly related to the concept of the network centrality of a node [22];

b) the "gravity-based" measures, so-called according to Newton's Universal Law of Gravitation, that define accessibility directly proportional to the number of activities/users located in the zones of the study area and inversely proportional to the generalized transport cost [11].

Accessibility to tourist attractions is mostly influenced by supply factors [23], represented by elements offered to attract tourists that may affect the perceived ease of access, such as infrastructure, services, communications, utilities and activities [24]. These include both tourist attraction functionality factors, such as staffing, car parking capacity, the presence of websites and the production of brochures [25], and facility factors, such as toilets, drinking water and picnic sites [26, 27], which may involve the choice of an attraction rather than the others [28]. Moreover, the accessibility to an attraction is affected by the quality of the transport networks to reach it [29] and the availability of alternative transport mode, e.g. train, bus, bike, etc. [30, 31].

Using the case of the Old City of Jerusalem, Israeli \& Mansfeld [32] investigated the interrelations between urban tourism and transportation systems needed to support tourist activities. The study first characterized the parameters influencing the level of accessibility of tourist flows to the main tourist attractions of Jerusalem. Subsequently, it looked at the most effective strategies of transportation management to be supported by appropriate infrastructure and means of transport.

Other variables that may explain the individual differences between tourists in their evaluation of accessibility to tourist attractions are: spatial abilities, individual needs and values, and preparatory information set. Spatial ability generally consists of two aspects, geographic knowledge and way-finding ability, which may be influenced by a range of factors in relation to the demographic characteristics of the tourist [33]. Factors such as the educational level on geographic capability [34], or the age or gender on way-finding [35, 36], have an indirect influence on differences of the tourists in the evaluating process of accessibility to the tourist attractions. According to Golledge \& Stimson [37], personal needs and values may affect an individual's perceptions and, consequently, a tourist's expectations about available activities at a given location and the decision to engage in them. Every individual has needs which arise partially from cultural values and social background which take shape from childhood, and partially from motivation factors, related to the education environment, the financial situation, the age [38] or to the research of new knowledge, adventure, enjoyment [39]. The preparatory set, which consists in a collection of prior information of tourist attractions obtained from different sources, e.g. web, newspapers, television or previous experiences $[40,41]$, has an influence on tourists' perceptions of accessibility [37].

In contrast to such a large body of literature focusing on the theoretical issues of tourist accessibility, the extent to which such theory is applied into practice is questionable. In fact, only a small number of studies relates accessibility to tourism. Application on a largescale network are mainly based on geographical information system (GIS) analysis. For example, Chhetri \& Arrowsmith [42] described a GIS-based technique to measure the recreational potential of a natural tourist destination located in Australia, based on a regression modelling used to develop a set of predictors of scenic attractiveness derived from data collected via questionnaire administered to a group of university students. Kong et al. [43] studied accessibility to open spaces in the urban environment, which have an important amenity values because they offer to tourist leisure opportunities and aesthetic enjoyment. The study, using GIS and landscape metrics, was conducted in Jinan City, a 7 million inhabitants' Chinese metropolis, where the value of urban green spaces gradually encroached upon by urban sprawl is increasingly important. Oh \& Jeong [44], using the network analysis method of GIS, analyzed pedestrian accessibility to urban parks in Seoul, where the total area is fairly large compared to those in other cities around the world, but they are located in an inconvenient location in the outer areas of metropolis, so that frequent opportunities to visit them are relatively minimal.

Starting from these considerations, the contribution of this paper to the literature is to identify an accessibilitybased methodology that can be efficiently applied on large-scale either from the (private) perspective of a tourist operator, to identify the suitable tourist attractions to be included in their tourist packages, or from the (public) perspective of a Public Administration, to identify areas to be further developed and where to invest in infrastructure, for tourist aims.

It is worth noting that the methodology here presented focuses on the international incoming tourist demand, consisting of the (in-hub) demand through the main airports, ports and railway stations, potentially attracted by 
the selected tourist sites of National and International interested identified by the Plan (i.e. the UNESCO heritage sites, the Italian Capitals of Culture and the EDEN sites). However, the methodology proposed could be applied to other contexts (e.g. regions and metropolitan areas) and with respect also to other demand segments.

In general, it is possible to have different geographical scales for application of the accessibility indicators (urban, regional, national); in this paper we deal with a national spatial context, but the methodology can be easily transferred to the regional level, for example, for the assessment of the priority investments within the regional transport plans. To authors' knowledge, the application at the national scale of an accessibility-based methodology for the assessment of tourist policies is original in the panorama of accessibility analysis.

\section{The proposed methodology}

The proposed methodology aims at identifying the tourist areas which presents a gap of accessibility, and at assessing the most appropriate type of investments (infrastructure or services) to improve sustainable tourist accessibility. ${ }^{1}$ Starting from these assumptions the methodology consists of three steps:

1. identification of the access gates (origins) and of the tourist sites relevant for the analysis (destinations),

2. modeling accessibility for the identified tourist sites from the access gates, using road network and public transport services,

3. assessment of the tourist sites which require an upgrading of accessibility either in terms of infrastructural connections (e.g. new road) or in terms of travel services.

\subsection{Phase 1: identification}

The first phase consists of the identification of the tourist sites and the access gate, relevant for the analysis. It is worth noting that both have been identified within the Plan for Tourist Mobility by the Ministry of Cultural Heritage and Activities and of the Tourism, and the Ministry of Infrastructure and Transport, according to specific criteria. They represent an input for our application.

In fact, the tourist sites have been identified among the Italian UNESCO Heritage sites (http://www.unesco. it/), the Italian Capitals of Culture (https://ec.europa.eu/ programmes/creative-europe/actions/capitals-culture_it) and the Italian EDEN destinations (i.e. the European Destinations of Excellence, https://ec.europa.eu/growth/ sectors/tourism/eden_it).

\footnotetext{
${ }^{1}$ The methodology has been adopted in the Italian Plan for Tourist Mobility [3].
}

The identification of the access gates (Fig. 1) has been carried out, within the Plan, by including: the airports classified as first-level airports in the Italian National Plan for Airports; the ports with a cruise traffic annual flow above the threshold of 300.000 passengers/years, and the stations served by High-speed Rail (HSR) services, provided that the demand of international tourists using HSR services is constantly increasing in Italy [45].

\subsection{Phase 2: modeling}

In the second phase, the accessibility of the identified destinations with respect to identified origins (i.e. the access gates) is measured. To this aim two accessibility measure are proposed. The first one is derived from the definition of "accessibility as a potential" [11] according to which two types of indicators can be defined $[8,46]$ :

a) individual (or "active") accessibility, which reflects the opportunity for people in a given place to participate in the activities located in different zones of study area,

b) place (or "passive") accessibility, which links the accessibility of a given activity (e.g. a tourist attraction) to the potential users located in different zones of the study area.

In our case, the following "place accessibility" indicator is firstly considered:

$$
A c c(d)^{m}=\sum_{o \in O} D(o)^{\alpha 1} \cdot \exp \left(-\alpha 2 \cdot C^{o, d, m}\right)
$$

where

- $A c c(d)^{m}$ is the accessibility of the tourist site " $d$ " using the transport mode " $m$ ";

- $D(o)$ is the demand of tourists generated from zone "o" (e.g. from the access gates);

- $C^{0, d, m}$ is the generalised travel cost on the shortest path between zones " $o$ " and " $d$ ", using mode " $m$ ";

- $\alpha 1$ and $\alpha 2$ are two estimated parameters to be adapted to the scope of the analysis (see for instance, [13]).

Note that the demand of tourists generated from zone "o", $D(o)$, has not been estimated using a model, but rather using the source data available from the international incoming demand at each access gate (ports, airport and railway stations). Although this does not represent the exact demand flow for tourist purpose, it can be assumed as an accurate proxy to the scope of the analysis.

Provided that it is fundamental that the accessibility indicator could be understandable and interpretable 


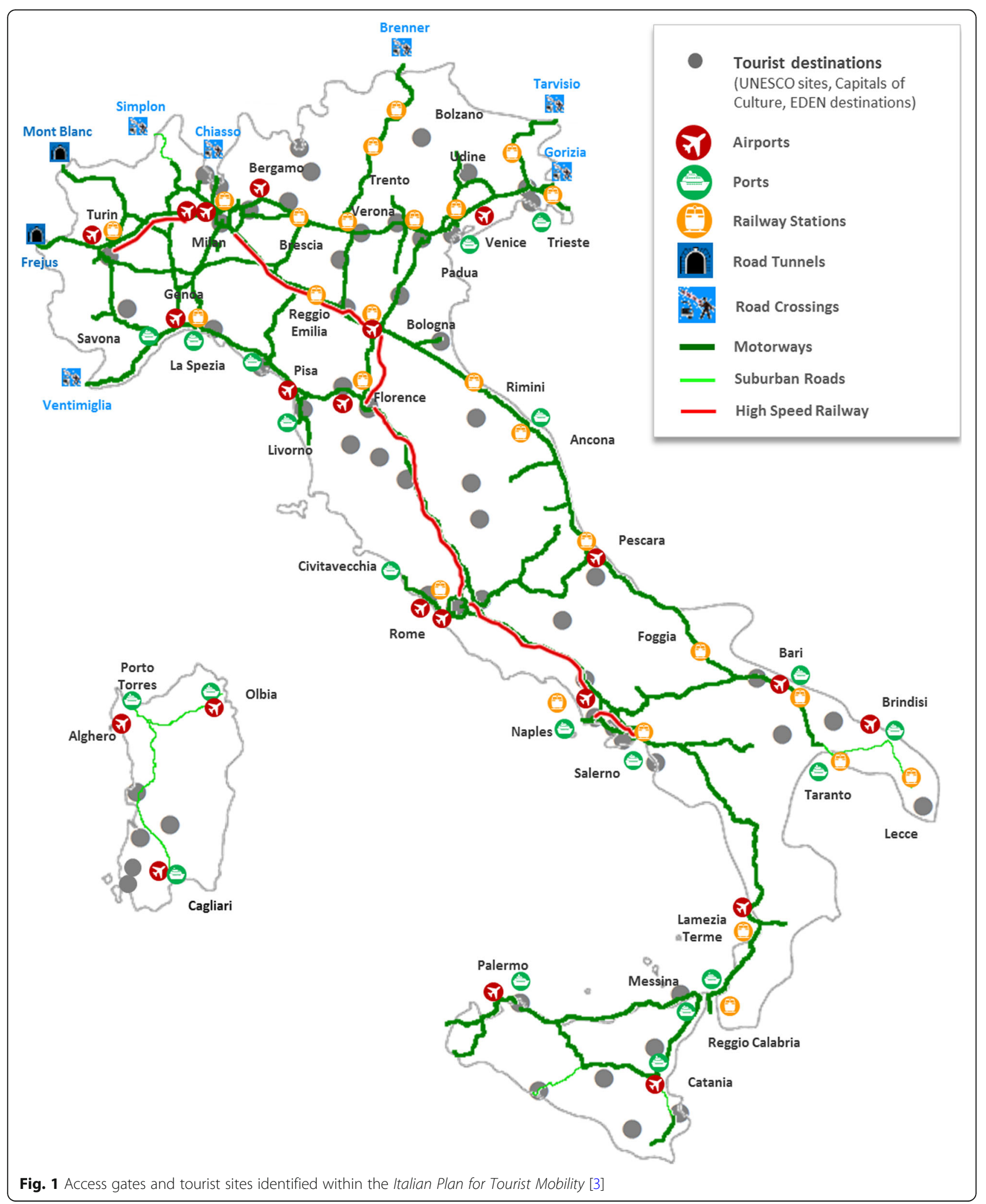

[47], a second indicator more explicitly linked to the access travel times and costs by cars and public transport is proposed, in order to convert the accessibility concept into numerical values more closely related to the objectives of the analysis [48]. To this aim, the following average access time is considered: 


$$
\operatorname{Acc} \operatorname{Cost}(d)^{m}=\frac{\sum_{o \epsilon O} D(o) \cdot C^{o, d, m}}{\sum_{o \epsilon O} D(o)}
$$

where:

- $\operatorname{Acc} \operatorname{Cost}(d)^{m}$ is the (average) access generalized travel cost to reach the tourist site " $d$ " from the access gates, using the transport mode " $m$ ";

- $D(o)$ is the potential demand of tourists generated from zone " $O$ " (i.e. the access gates);

- $C^{o, d, m}$ is the generalised travel cost on the shortest path between zones " $o$ " and " $d$ ", using mode " $m$ ".

Eq. (1) represents a "place-based" accessibility indicator while Eq. (2) represents an average access cost towards a given destination " $\mathrm{d}$ ". The two measures applied to the same study actually do show opposite patterns, i.e. the higher the access cost (Eq. 2), the lower the accessibility (Eq. 1). They could be used alternatively. In fact, the A-G diagram is adapted accordingly to each of them. In the application presented in Section 4 we opted for the Access Cost (Eq. 2).

Both the above indicators require the computation of the generalized travel cost on the shortest path between two generic zones [49]. The algorithm is based on the iterative correction of the tree structure $T(o)$ - having root the origin node " $o$ " - and verifying at each iteration the satisfaction of the condition expressed by Bellman's theorem [50]:

$$
C_{T(o), i}+c_{i j} \geq C_{T(o), j} \quad \forall(i, j) \in T(o)
$$

being:

- $C_{T(o), i}$ the generalized travel cost from the origin node $o$ to the node $i$ in the tree $T(o)$;

- $C_{T(o), j}$ the generalized travel cost from the origin node $o$ to the node $j$ in the tree $T(o)$;

- $c_{i j}$ the generalized travel cost of the generic section having $i$ and $j$ for extreme nodes.

Similarly, to compute the shortest paths on the integrated public transport network, the identification of minimum cost paths is carried out by an extension of Dijkstra's algorithm [51].

The generalized transport cost is computed using two different cost functions: one for the road network and the other for the integrated Public Transport (PT) system.

\subsubsection{Generalized travel costs on the road network}

For the road network, the transport cost, $C^{o, d, R o a d}$, is given by the sum of the travel time, $t$, and the monetary cost, $\mathrm{cm}$, the minimum path $k_{\text {min }}$ weighed by the coefficients $\beta_{c}$, adapted from the literature on value of time and assumed equal to 0.10 (hour/euro), transforming cost (euros) in time (hours):

$$
C^{o, d, R o a d}=t_{k_{\text {min }}}^{o, d}+\beta_{c} \cdot c m_{k_{\text {min }}}^{o, d}[\text { hours }]
$$

The travel time depends on the speed and the presence of congestion on the different typologies of sections (motorway, suburban road, etc.) of the road network, whereas the monetary cost is the sum of the operating cost and the toll (if any) on section, $s$, estimated by the vehicle type, $v$ :

$$
c m_{k}=\sum_{v} \sum_{s \in k}[\underbrace{\left(C c_{s, v}+C l+C t+C o\right)}_{\text {operating cost }}+\underbrace{C p_{s, v}}_{\text {toll }}] \cdot L_{k}
$$

being:

- $L_{k}$ the length of path $k$ expressed in kilometers;

- $C c_{s, v}$ the fuel cost on section $s$ for vehicle class $v$, computed as:

$$
C c_{\mathrm{s}, v}=\frac{c_{s, v} \text { fuel_cost }}{\gamma_{v}} \quad[€ / k m]
$$

where:

- fuel_cost $t_{v}$ is the unitary cost of the fuel for vehicle type $v$ (petrol vs. diesel);

- $c_{s, v}$ is the average fuel consumption estimated based on average speed on section $s, \mathrm{~V}_{\mathrm{s}}$, through the CORINAIR $^{2}$ model [53], according to pollutant emissions regulation $\eta$ and the percentage number of vehicles $d_{\eta}$ (Euro $0,1, \ldots$ ) for both the motorway cycle (Table 3) and the urban and sub-urban cycle (Table 4):

$$
\begin{aligned}
c_{s, v} & =\frac{\sum d_{\eta} \cdot c_{\eta, s}}{\sum d_{\eta}} \quad[\mathrm{gram} / \mathrm{km}] \\
c_{\eta, s} & =a_{\eta} \cdot V_{s}+b_{\eta} \cdot V_{s}^{2}+k_{\eta}
\end{aligned}
$$

${ }^{2}$ Note that the emission factors estimated using CORINAIR might be outdated in some contexts; recently the European Environmental Agency (EEA) has released the technical guidance to prepare national emission inventories e to create an updated air pollutant emission inventory guidebook [52]. 
Table 3 parameter of the Corinair model for fuel consumption of cars on motorway

\begin{tabular}{llll}
\hline Regulation $\eta$ & $a_{\boldsymbol{\eta}}$ & $b_{\boldsymbol{\eta}}$ & $k_{\boldsymbol{\eta}}$ \\
\hline PRE ECE & 0.471 & 0 & 29.286 \\
ECE 15-00/01 & -0.407 & 0.0042 & 59 \\
ECE 15-02/03 & -0.7032 & 0.0059 & 71 \\
ECE 15-04 & -1.364 & 0.0086 & 102.5 \\
\hline
\end{tabular}

$-\gamma_{v}$ is specific weight of the fuel for petrol and diesel vehicles, equal respectively to 740 and $825 \mathrm{~g} /$ liter.

- $\mathrm{Cl}, \mathrm{Ct}$, Co represent respectively the lubricants cost, the tires cost and the maintenance cost for vehicle type $v$, assumed respectively equal to 0.00576 , 0.01507 and 0.04035 ;

- $C p_{s, v}$ is the toll on section $s$ and for each vehicle class $v$, i.e. vehicles with two axles (class es A and B) and vehicles with more than two (classes 3, 4 and 5).

\subsubsection{Generalized travel costs by public transport}

In the case of public transport, the generalized cost has been computed on the" minimum hyperpath" $K$ for the generic origin-destination pair (od) which represents the average cost that travelers do perceive over all the paths on the Public Transport network connecting a given origin-destination pair, weighted by the relative frequencies of the service [51]. This is obtained as follows:

$$
C^{o d, P T}=T_{b}^{o d}+\beta_{c m} \cdot c m_{s}^{o d}+\beta_{\phi} \cdot \phi^{o d}[\text { hours }] .
$$

The boarding time, $T_{b}$, depends on the commercial speed of the public transport service which is in turn a function of the vehicle's type (e.g. High-speed Rail, intercity or regional rail services; regional or interregional bus services), (train or bus). The monetary cost, $\mathrm{cm}$, depends on the fare systems of the PT service available on the od pair and is computed as the sum of two components:

$$
\left.c m_{s}^{o d}=c m_{K_{s}}^{o d}+c m_{\text {dists }} \cdot \text { dist }^{o d} \quad \text { [euros }\right]
$$

being the first component, $c m_{-} K$, a constant depending on the type of service and on the $o d$ pair; and the second component the product of the travelled distance (in $\mathrm{km}$ ),

Table 4 Corinair's model for fuel consumption of cars on urban and suburban roads

\begin{tabular}{lll}
\hline Regulation $\eta$ & Suburban roads & Urban roads \\
\hline PRE ECE & 67 & 118.754 \\
ECE 15-00/01 & 50.29 & 109.346 \\
ECE 15-02/03 & 50.22 & 101.683 \\
ECE 15-04 & 50.18 & 82.178 \\
\hline
\end{tabular}

dist, and the unitary cost per kilometer, cm_dist, depending on the PT service (bus or train). Finally, the generalized cost function includes the service frequency, $\phi$, as proxy of the waiting time for high-frequency services and of the scheduled early and late departure penalty for low-frequency services [54]. The parameters $\beta_{c m}$ and $\beta_{\phi}$ have been adapted from the literature and assumed equal respectively to 0.125 (hour/euro) and 0.33 $\left(\right.$ hours $^{2}$ ).

\subsection{Phase 3: assessment (the "AG-Diagram")}

The third phase of the method aims at identifying the sites that need an upgrading of accessibility either in terms of infrastructural connections (e.g. new roads or railways) or in terms of public transport services. To this aim, the accessibility indicator (or the generalized access travel cost) are plotted in a diagram, so called the "Accessibility Gap" (AG) diagram, reporting for each tourist site the accessibility on the road network (on $\mathrm{x}$-axis) and the accessibility using the Public Transport system (on the y-axis).

Having set a threshold for accessibility, it is possible to recognize four quadrants (Fig. 2):

- the 1st quadrant, at the top on the right, includes sites having a good level of accessibility both on public transport and on the road network,

- the 2nd quadrant, at the top on the left, includes those sites with good level of accessibility by public transport but with limitation of access by car (for example, the sites located in zone with restrictions to car),

- the 3rd quadrant, at the bottom on the left, includes sites with low accessibility levels both by car and by public transport, i.e. zones with accessibility gaps,

- the 4th quadrant, is characterized by low accessibility by public transport services and high accessibility by car, i.e. zones where improvement of public transport services are required.

Using the above diagram, which represents a framework for the analysis of the estimated accessibility values, it is possible to identify the specific type of intervention for each site included in the analysis. In fact, sites and tourist areas falling in the first quadrant are those do not require priority interventions on infrastructures and mobility services, given the good level of accessibility both on private and public transport. Sites falling in the second quadrant are those located in very congested area or area with restricted access by car; no specific intervention are required in these cases, as well. On the other hand, sites falling in the third quadrant requires an infrastructural upgrading of the access network (road and/or railway) to improve the accessibility 


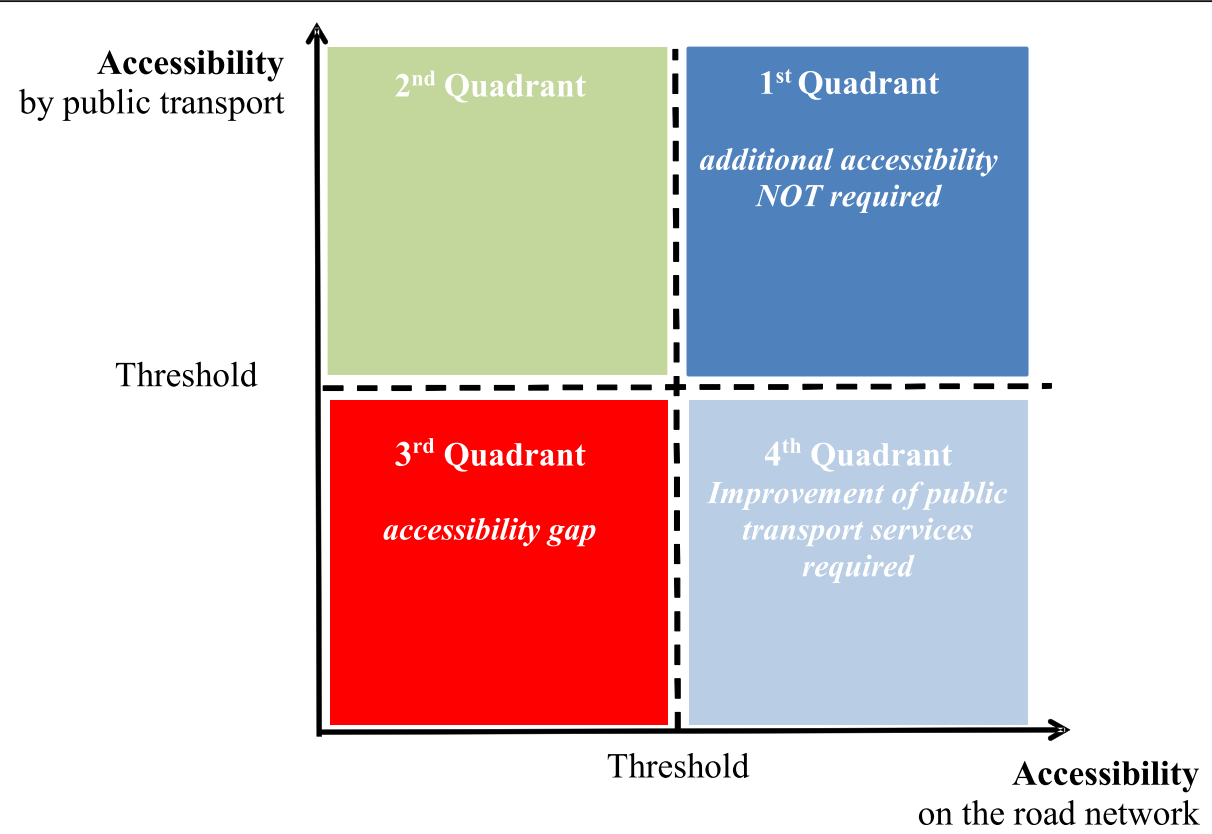

Fig. 2 the Accessibility Gap diagram for differential analysis of public vs private transport accessibility

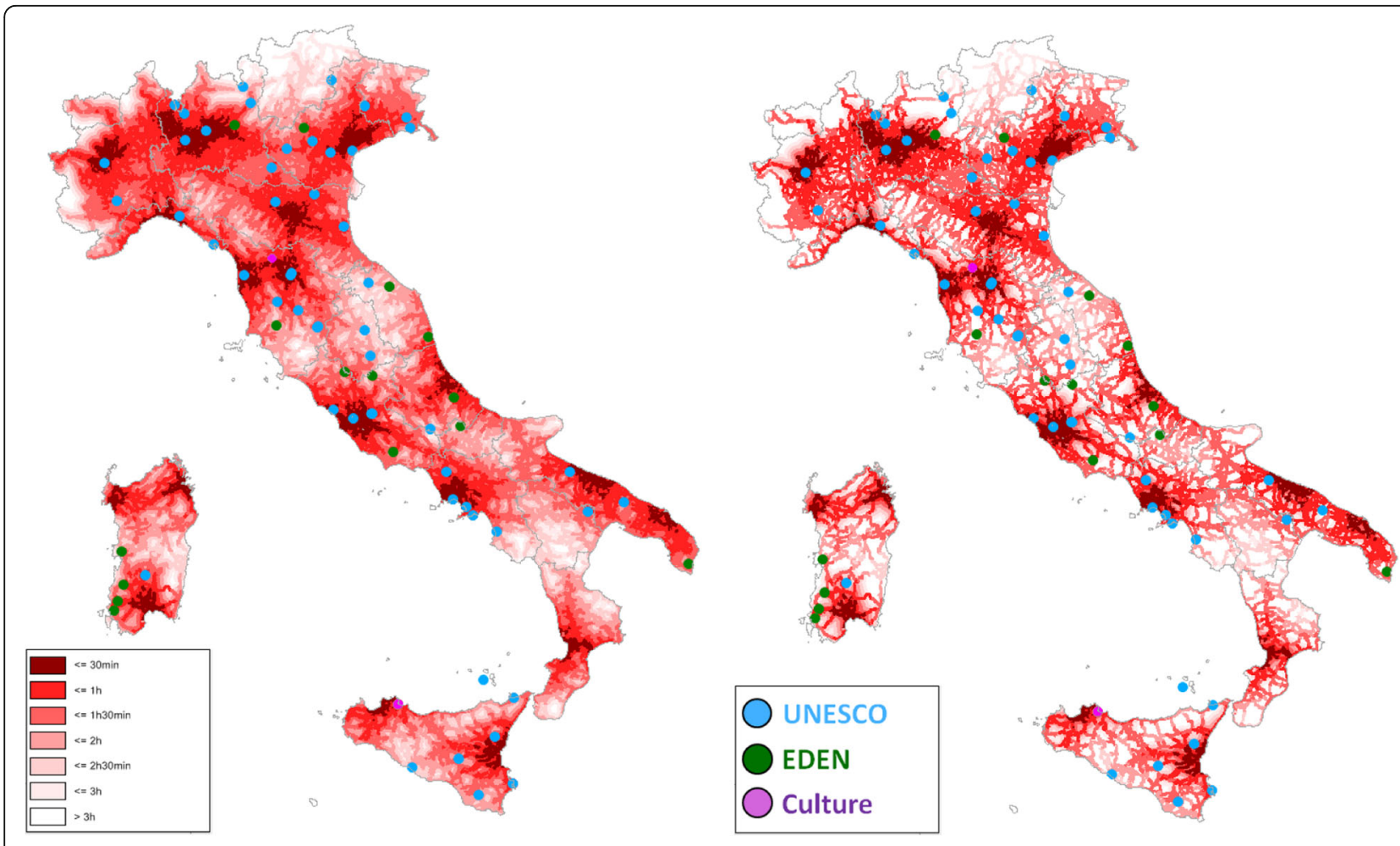

Fig. 3 travel times from the main airports to the selected tourist sites, on the road network (on the left) and using public transport (on the right) 
primarily on the road network and then on the public transport service to bridge up the accessibility gap. Finally, sites falling in the fourth quadrant are those requiring an upgrading of public transport services, given the presence of an infrastructural network that allows a good level of accessibility on the road network.

\section{Application}

An application of the method described in Section 3, was carried out within the framework of the Italian Plan for the Tourist Mobility. It is worth noting that, the application here presented focuses on the international incoming tourist demand, consisting of the (in-hub) demand through the "access gates" (see Fig. 1), potentially attracted by the tourist sites identified by the Plan, i.e. the UNESCO heritage sites, the Italian Capitals of Culture and the EDEN destinations (see section 4.1). Other tourist segments, have not been considered although relevant, however the methodology proposed could be applied to other contexts (e.g. regions and metropolitan areas) with respect also to other demand segments. In these cases, a different transport model (e.g. a regional transport model) and more disaggregate data (e.g. Census data at the level of municipalities) would be needed to compute the accessibility values.
The analysis of travel times from the airports (Fig. 3) show a good level of accessibility spread over almost the whole national territory, with the exception of the Trentino Alto-Adige region in the North-East, the Basilicata region and the Southern parts of the Calabria region due to poor connections with the Lamezia Terme airport. Overall the $97 \%$ of the considered tourist sites are reachable, using the road network, from the nearest airport in less than $2 \mathrm{~h}$ and more than half of these (i.e. 40 sites) in less than $1 \mathrm{~h}$. Besides, only $40 \%$ of the sites can be reached, using public transport, from the nearest airport in less than $2 \mathrm{~h}$ and only 8 of these in less than an hour.

The analysis of travel times from the ports (Fig. 4) show a good level of accessibility spread over the national territory, thanks to the presence of numerous access gates on both Tyrrhenian and Adriatic coasts. An exception is represented by the Alpine arc, due to the long distance from the closest ports on the North Tyrrhenian ports, on the one side, and from the NorthAdriatic ports, on the other side. Overall, the $80 \%$ of the considered tourist sites can be reached from the nearest port in less than $2 \mathrm{~h}$ on the road network, even if most of these (i.e. 31 sites) are still more than $1 \mathrm{~h}$ far away. Besides, it takes two or more hours to reach the majority of the considered sites (66\%) using public transport, and only eight sites are within $1 \mathrm{~h}$ from the nearest port.

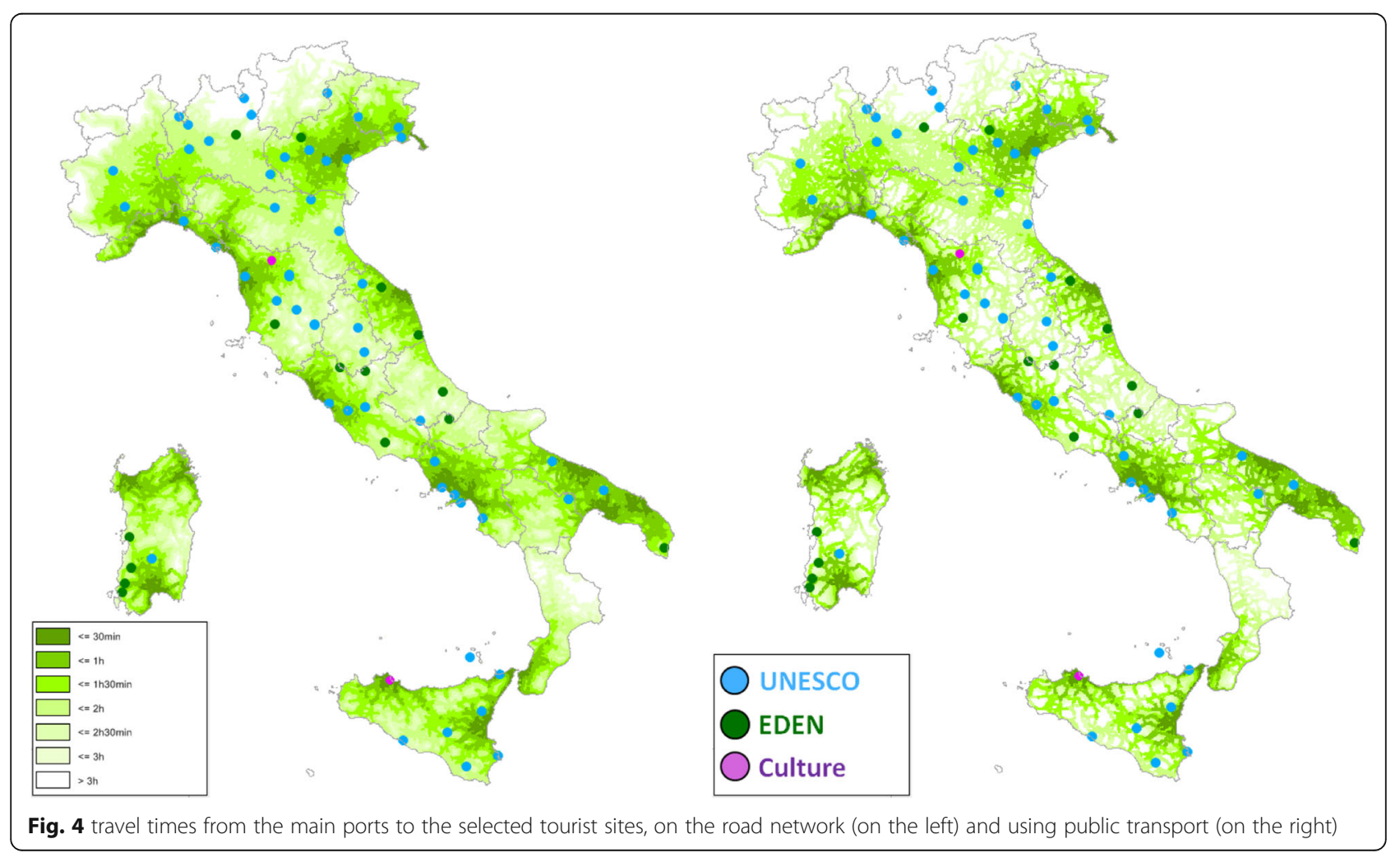




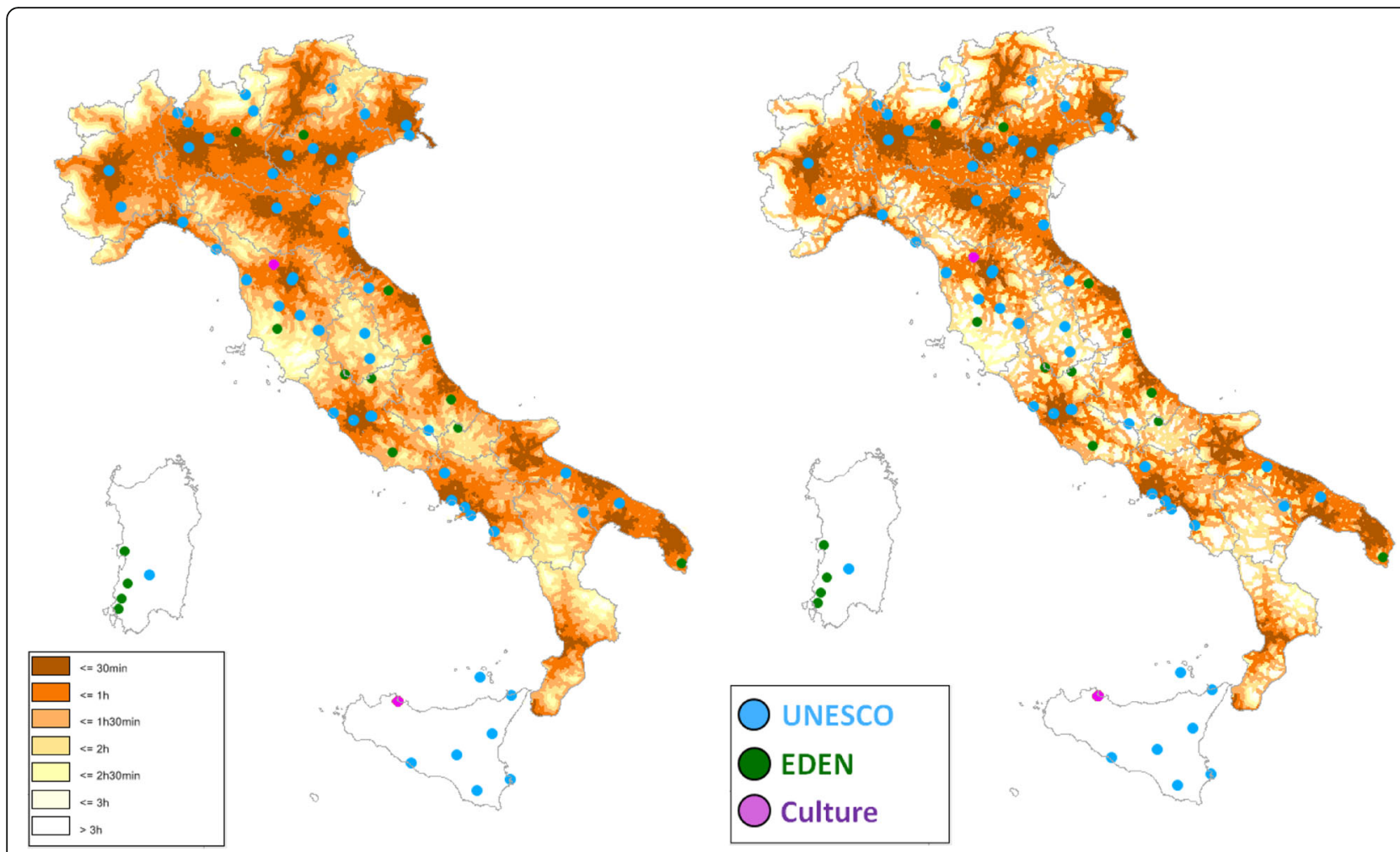

Fig. 5 travel times from the main railway stations to the selected tourist sites, on the road network (on the left) and using public transport (on the right)

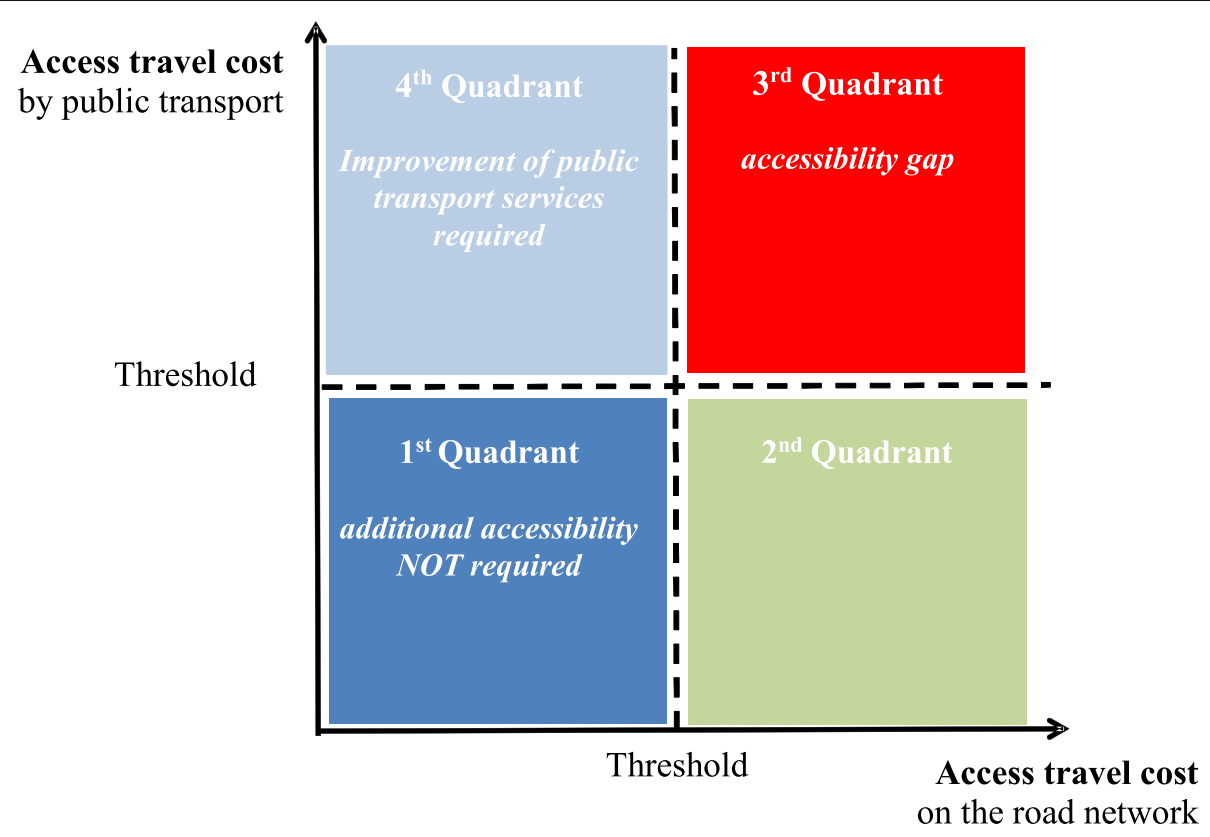

Fig. 6 The Accessibility Gap diagram for differential public vs private transport access travel cost 
The analysis of travel times from the railway stations (Fig. 5) show an excellent level of accessibility diffuse over almost the entire peninsular territory, with the exception of very small areas in the lower part of Tuscany and the border area between Basilicata and Calabria, which is clearly counterbalanced by the lack of accessibility to the island sites, due to the absence of Highspeed Rail service. Generally speaking, if we keep out the analysis, the 13 tourist sites in Sicily and Sardinia, most of the remaining sites (68\%) can be reached by car in less than an hour from the nearest railway station and 20 of these even in less than half an hour. On the other hand, only $35 \%$ of the 57 peninsular tourist sites can be reached by public transport in less than an hour and only 10 of these are within half an hour from the nearest railway station.

The accessibility gap analysis was carried out by means of the access generalized travel cost functions (see Eq. 2 ), on the road network and using public transport. Note that when using a travel cost function instead of an accessibility indicator, the same consideration as described in section 3 may apply, but the definition of the quadrants follow a different scheme (Fig. 6), given that access travel costs are negatively perceived by travelers, whereas accessibility positively.

The access travel costs of the considered tourist sites, aggregated by macro-areas (Table 5 ), allow the following considerations. Overall, it can be observed that the accessibility from the airports is better than from the ports. In fact, on the National basis, it is estimated an average travel access cost on the road network of $60 \mathrm{~min}$ from the airports and $80 \mathrm{~min}$ from the ports (Fig. 7), and an average travel access cost using public transport of 135 min from the airports and $145 \mathrm{~min}$ from the ports (Fig. 8). Northern-east and Northern-west sites (including those located in the Alps) are less accessible both from airports and from ports, whereas the sites located on the islands (Sicily and Sardinia) are poorly connected to the airports.

The National Plan of Tourist Mobility (see Section 2) set a threshold of $1.5 \mathrm{~h}$ under which all the main tourist

Table 5 the macro-areas of the national territory

\begin{tabular}{ll}
\hline $\begin{array}{l}\text { Macro- } \\
\text { area }\end{array}$ & Italian Regions (NUTS2) \\
\hline $\begin{array}{l}\text { North- } \\
\text { West }\end{array}$ & Aosta Valley, Piedmont, Lombardy, Liguria \\
North-East & $\begin{array}{l}\text { Trentino Alto-Adige, Veneto, Friuli-Venezia Giulia, Emilia } \\
\text { Romagna }\end{array}$ \\
\begin{tabular}{ll} 
Center & Tuscany, Umbria, Marche, Lazio \\
South & Abruzzo, Campania, Basilicata, Molise, Calabria, Apulia \\
Islands & Sardinia, Sicily \\
\hline
\end{tabular}
\end{tabular}

sites ought to be reached from the access gates (i.e. the main national airports, ports and railway stations). To identify those sites that are beyond this threshold either using the public transport service or using the road network, the travel access costs to the selected tourist sites from the airports (Fig. 9), the ports (Fig. 10) and the railway stations (Fig. 11) have been plotted in the Accessibility-Gap diagram (see section 3.3).

It can be observed (Table 6) that there are no tourist sites falling in the 2nd quadrant (where travel access costs by Public Transport is lesser than by private transport) and that there is more than a third of the tourist sites $(40 \%)$ that do not require additional accessibility (1st quadrant). The analysis suggests that the connections by Public transport need to be improved (particularly from the ports) for almost half $(42 \%)$ of the tourist sites. Finally, for about $18 \%$ of the selected tourist sites (those falling in the 3rd quadrant) there is an accessibility gap that need to be bridged up by means of infrastructural interventions either on the road network or on the railway connections.

\section{Discussion and conclusions}

This paper presents a methodology, developed within the Italian National Plan of Tourist Mobility, aiming at identifying tourist areas with poor accessibility from the main national airports, ports and railway stations (i.e. the "access gates" of the international tourists). The focus of the paper is not on how to compute the generalized travel cost and the accessibility for tourist purposes, but rather to combine the two's measures (extensively studied in the literature) to develop a method to support decision-makers to identified where and how to invest (e.g. in services or infrastructure? public transport or roads?) in order to improve the accessibility to a selected number of tourist sites.

The state of the art has shown that while there is a large body of literature focusing on tourist choices, preferences and needs, accessibility indicators are rarely applied to drive tourist policies, as also pointed out by OECD report on the indicators for measuring tourist competitiveness [55]. The fact that the methodology has been adopted and applied within a national plan proves that accessibility-based methodology can be efficiently applied on the large scale to identify areas to be further developed and where to invest for tourist aims. To authors' knowledge, the application at the national scale of an accessibility-based methodology for the assessment of mobility policies for tourism is original, in the panorama of the accessibility analysis.

Moreover, the paper shows the potential and the usability of the accessibility concept in tourist planning, and confirm that accessibility instruments are applicable 


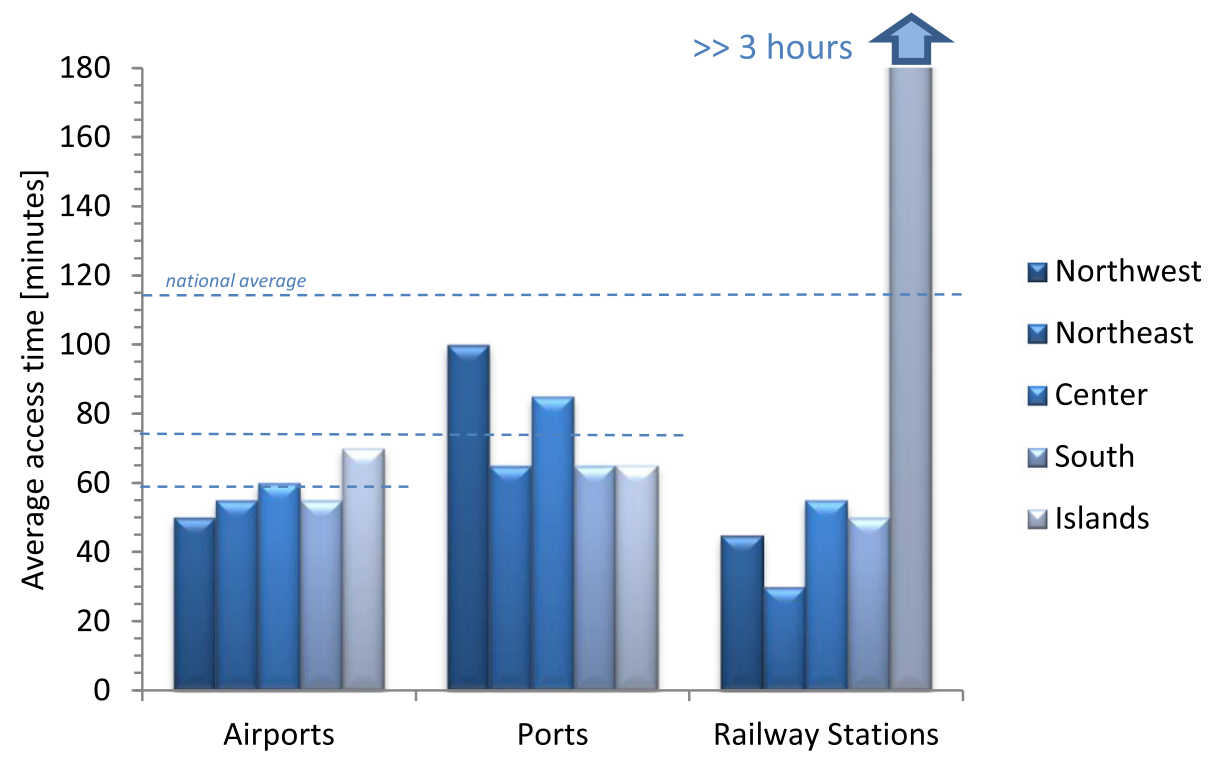

Fig. 7 average access travel costs (expressed in minutes) on the road network

in practice when they are included in a modeling framework easy to be interpreted by decision-makers, and directly linked to policy actions.

The methodology consists of three phases: the identification of the access gates (origins) and of the tourist sites relevant for the analysis (destinations), the estimation of the accessibility by car and public transport services for the identified tourist sites from the access gates, and, finally, the assessment of the accessibility gaps either in terms of infrastructural connections or in terms of mobility services. The socalled Accessibility-Gap diagram, reporting for each site a measure of accessibility on the road network (on the $\mathrm{x}$-axis) and using public transport (on the $\mathrm{y}$ axis), has been introduced to assess where there is an accessibility gap and whether this ought to be bridged up by improving mobility services and/or by building new infrastructure.

The use of concepts such as the generalized transportation cost and the place accessibility, extensively studied

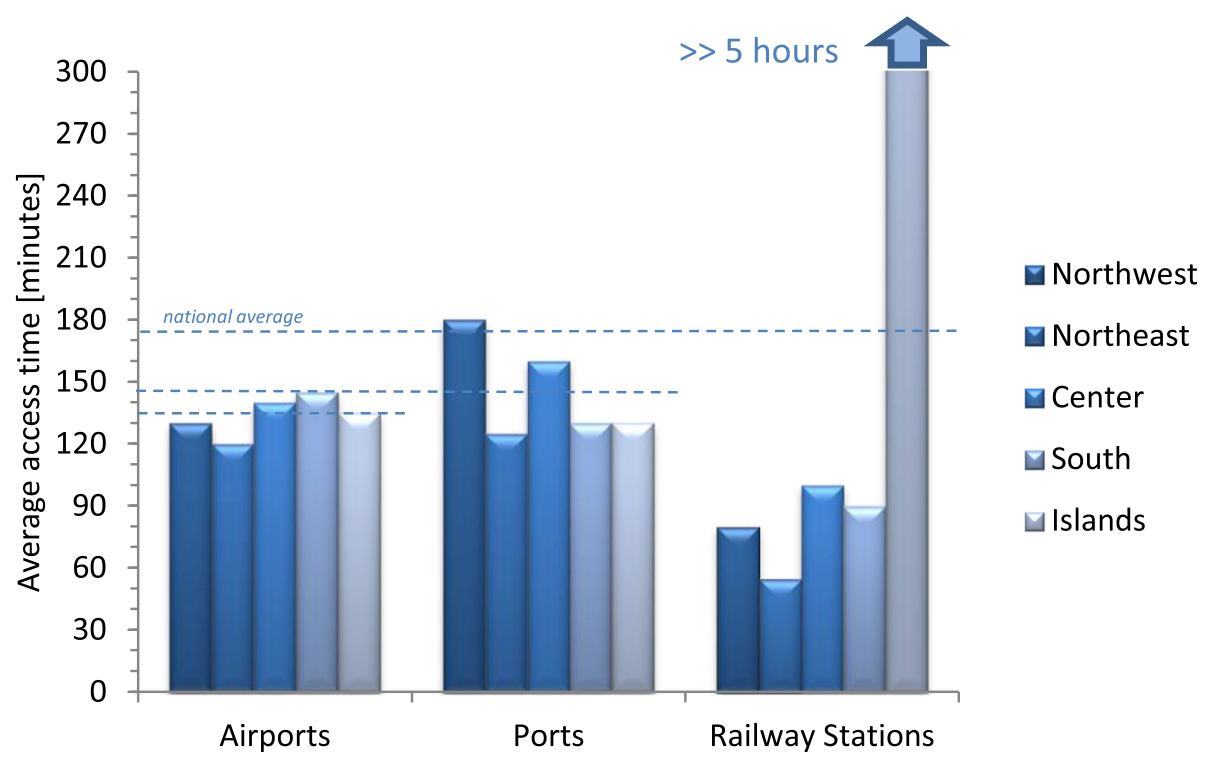

Fig. 8 average access travel costs (expressed in minutes) using public transport 


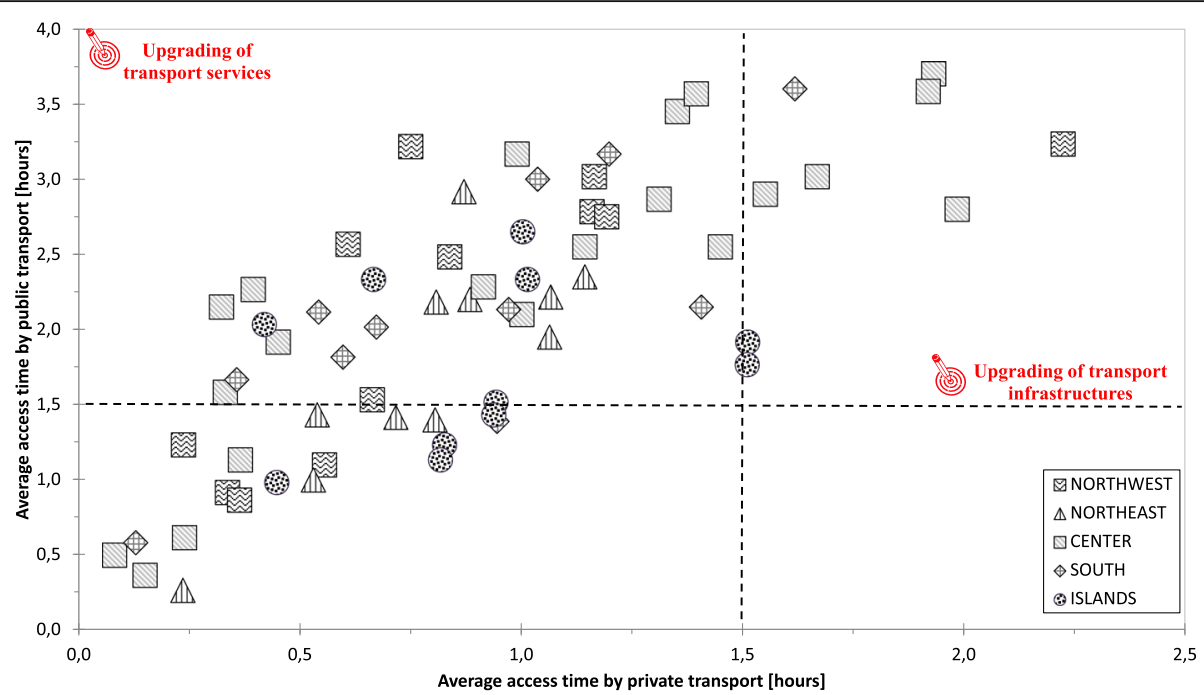

Fig. 9 AG Diagram (from the main national airports)

in spatial and transportation planning has been key for the adoption and the implementation in the Plan, even with some limitations from the academic perspective.

In particular, the Accessibility-Gap diagram requires the definition of a threshold to identify zones with low and high accessibility. In principle, the threshold should be defined based on the trade-off between, on the one hand, the increase in the number of tourists attracted (and the induced economic benefits) due to improved accessibility conditions, and, on the other hand, the economic investment needed for such improvement. In short, the lower the threshold the more the number of tourist sites with an accessibility gap and the more the economic investment required to cope with that. In the application here presented, the threshold of $1.5 \mathrm{~h}$ has been considered based on the policy objective of the Plan which sets up the target of $1.5 \mathrm{~h}$ as maximum travel time from the "access gates" (i.e. airports, ports, HSR stations) for the UNESCO heritage sites, and the Italian Capitals of Culture and the EDEN destinations. The value was set in consideration of the fact that $1.5 \mathrm{~h}$ is the travel time which approximately allows tourist operators to organize a visit of a site within one single day. ${ }^{3}$ However, the fact of not having considered any cost-benefits trade-off in the definition of the target is questionable, and ought to be seen as a limitation of the analysis. Future research should investigate more in detail the impact of different thresholds on the economic investment

\footnotetext{
${ }^{3}$ In a different context, i.e. the analysis of intercity daily commuters using high-speed rail service in Italy, a similar value has been found [56].
}

in the attempt to verify the existence of any optimal balance.

Moreover, the methodology proposed is based on a gravity-based accessibility measures (GRABAMs) including the demand of tourists generated from the access gates, as the potential, and a decay function (negative exponential) of the generalised travel cost on the shortest path from the access gates to the tourist site, as impedance function. From the operational viewpoint, GRABAMs present some difficulties: in fact, they require the estimation of some parameters and of the potential function (see section 3.2 ) which could be cumbersome given the scale of analysis (nation-wide) and the number of tourist sites considered. Therefore, in the application, a second accessibility measure has been chosen, i.e. the (average) access travel cost to the tourist site. This present the advantages not only of being easier to be computed than GRABAMs, but also, and of utmost importance, that, being explicitly related to the threshold value, it is understandable by decision-makers and directly linked to one of the policy goals of the Plan.

The model has been applied to the Italian case study which represents a relevant example given the number of tourist sites scattered over the national territory. The results of the analysis carried out, suggest that the connections by public transport need to be improved (particularly from the ports) for almost half $(42 \%)$ of the considered sites; about $18 \%$ of the selected tourist presents an accessibility gaps that need to be bridge up by means of infrastructural interventions either on the road network or on the railways. Overall, it can be observed that the accessibility from the airports is better than from the ports. Besides, the sites located in the 


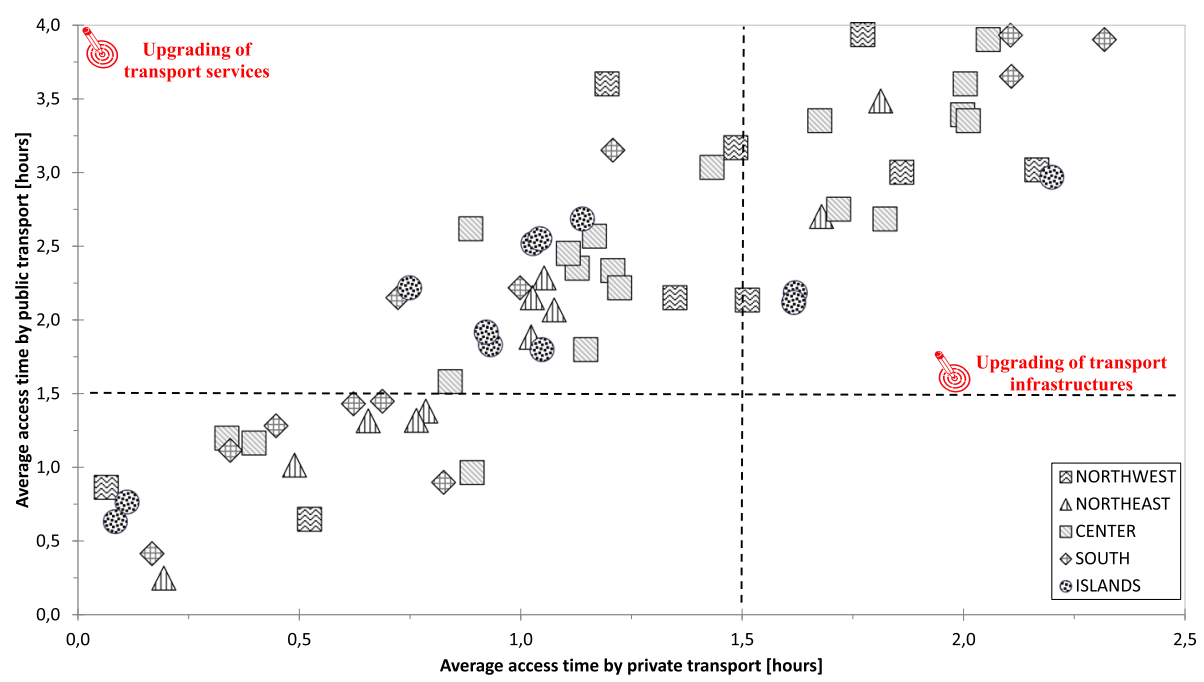

Fig. 10 AG diagram (from the main national ports)

South of Italy lack of public transport services. The sites located in the Center-Italy have better accessibility conditions particularly from the airports.

The results of the application have allowed to identify some investment priorities for tourist mobility in Italy. In fact, the Italian Ministry of Infrastructure and Transport based on such results have launched an investment program to improved ports and airports last mile connections and mass rapid transit systems, with attention also to the tourist destinations. The analysis focuses on road and public transport investments, which might appear to be rather a narrow perspective with respect to a broader concept of accessibility including digital and environmental aspects. In fact, a "digital-oriented" and "sustainable" approach to develop a tourist mobility is foreseen in the Plan under the policy goals of "Digitalization" and "Sustainability". Actions are proposed to optimize the access to tourism by means of advanced traveler information systems providing efficient, reliable and seamless travel solutions, and to improve tourists' experience even before the travel starts, as well as models of sustainable tourist mobility such as, the national network of cycling and pedestrian integrated routes connecting the tourist sites. Indeed, tourism is an important asset for Italy, and future research contribution should help to further develop the Plan in order to valorise the resources of the Country, contributing to its economy, without compromising its sustainability.

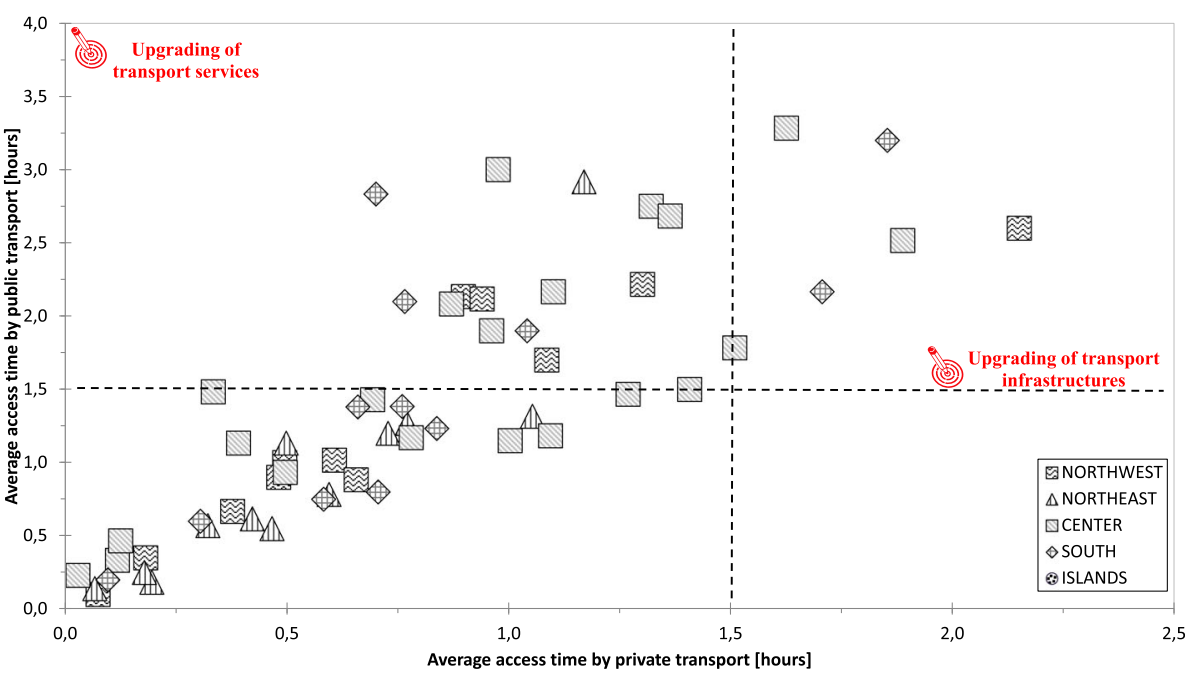

Fig. 11 AG diagram (from the main national railway stations) 
Table 6 percentage distribution of the considered tourist sites by quadrants in the AG-diagram

\begin{tabular}{llllll}
\hline $\begin{array}{l}\text { Access travel } \\
\text { cost from }\end{array}$ & $\begin{array}{l}\text { 1st } \\
\text { Quadrant }\end{array}$ & $\begin{array}{l}\text { 2nd } \\
\text { Quadrant }\end{array}$ & $\begin{array}{l}\text { 3rd } \\
\text { Quadrant }\end{array}$ & $\begin{array}{l}\text { 4th } \\
\text { Quadrant }\end{array}$ \\
\hline Airports & $29 \%$ & $0 \%$ & $14 \%$ & $58 \%$ & $100 \%$ \\
Ports & $29 \%$ & $0 \%$ & $30 \%$ & $41 \%$ & $100 \%$ \\
$\begin{array}{l}\text { Railway Stations } \\
\begin{array}{l}\text { Weighted } \\
\text { average }\end{array}\end{array}$ & $\mathbf{4 0 \%}$ & $0 \%$ & $11 \%$ & $26 \%$ & $100 \%$ \\
\hline
\end{tabular}

Finally, it is worth to mention that although the analysis has been carried out at the national territorial scale, the methodology is easily replicable and transferable even at the local level, and in the future, it could be applied for the assessment of the priority investments within the regional transport plans.

\section{Acknowledgements}

Not applicable.

\section{Authors' contributions}

The contribution to the paper is as follows: Pierluigi Coppola: study conception and methodology; state-of-art; application and analysis of the results; Armando Carbone: state-of-art; accessibility analysis and access travel costs estimation; Carmine Aveta: application and analysis of the results; Piera Stanghelin: data collection and analysis of the results. All authors reviewed the results and approved the final version of the manuscript.

\section{Funding}

Not applicable.

\section{Availability of data and materials}

Most datasets used and/or analyzed during the current study are available from the corresponding author on reasonable request. Restrictions apply to the availability of data that was used under license for the current study, and so are not publicly available. This data is however available from the authors upon reasonable request and with permission of the Italian Ministry of Infrastructure and Transport.

\section{Competing interests}

The authors declare that they have no competing interests.

\section{Author details}

${ }^{1}$ Polytechnic of Milan, Department of Mechanical Engineering, Via G. La Masa 1, 20156 Milan, Italy. ${ }^{2}$ Italian Ministry of Infrastructure and Transport, Technical Special Unit, Via Nomentana 2, 00187 Rome, Italy.

Received: 22 May 2020 Accepted: 28 August 2020

Published online: 12 October 2020

\section{References}

1. ISTAT (2018). Tourist movements in Italy in year 2017. Italy: Italian National Institute for Statistics https:/www.istat.it/it/files/2018/11/report-movimentoturistico-anno-2017.pdf.

2. MIBACT (2016). Strategic plan for the development of the tourism: Italy, country for travelers. Italy: Ministry of Cultural Heritage and Activity and of the Tourism https://www.beniculturali.it/mibac/multimedia/MiBAC/ documents/1481892223634_PST_2017_IT.pdf.

3. MIT (2017). Special plan of tourist mobility. Travelling in Italy. Italy: Ministry of Infrastructure and Transport http:/www.mit.gov.it/sites/default/files/media/ pubblicazioni/2018-01/piano\%20straordinario\%20mobilit\%C3\%A0\%2 Oturistica\%202017-2022\%20v0.pdf.

4. MIT (2016). Connecting Italy: strategies for Transport and Logistic Infrastructure. In Annex to the Economic and Finance Document 2016. Italy: Ministry of Infrastructure and Transport http://www.mit.gov.it/sites/default/files/media/ notizia/2017-06/Strategie\%20per\%20le\%20infrastrutture_2016.pdf.
5. Papa, E., Silva, C., Brommelstroet, M. T., \& Hull, A. (2016). Accessibility instruments for planning practice: A review of European experiences. Journal of Transport and Land Use, 9, 1-20.

6. Hull, A., Papa, E., Silva, C., \& Joutsiniemi, A. (2012). Discussion on accessibility instruments. In A. Hull, C. Silva, \& L. Bertolini (Eds.), Accessibility instruments for planning practice @ COST Office.

7. Silva, C., Bertolini, L., te Brömmelstroet, M., Milakis, D., \& Papa, E. (2017). Accessibility instruments in planning practice: Bridging the implementation gap. Transport Policy, 53, 135-145.

8. Geurs, K. T., \& van Wee, B. (2004). Accessibility evaluation of land-use and transport strategies: Review and research directions. Journal of Transport Geography, 12(2), 127-140. https://doi.org/10.1016/j.jtrangeo.2003.10.005.

9. Andersson, M., \& Karlsson, C. (2007). Knowledge in regional economic growth: The role of knowledge accessibility. Industry \& Innovation, 14, 129-149.

10. O'Kelly, M. (2007). The impact of accessibility change on the geography of crop production: A reexamination of the Illinois and Michigan canal using GIS. Annals of the Association of American Geographers, 97, 49-63.

11. Hansen, W. G. (1959). How accessibility shapes land use. Journal of the American Institute of Planners, 35(2), 73-76.

12. Burns, L. D. (1976). The role of accessibility in basic transportation choice behavior. Transportation, 5(2), 175-198.

13. Coppola, P., \& Nuzzolo, A. (2011). Changing accessibility, dwelling price and the spatial distribution of socio-economic activities. Research in Transportation Economics, 31(1), 63-71. https://doi.org/10.1016/j.retrec.2010.11.009.

14. Cordera, R., Coppola, P., dell'Olio, L., \& Ibeas, A. (2017). Is accessibility relevant in trip generation? Modelling the interaction between trip generation and accessibility taking into account spatial effects. Transportation, 44(6), 1577-1603.

15. Chien, S., \& Qiz, Z. (2004). Optimization of bus stop locations for improving transit accessibility. Transportation Planning and Technology, 27, 211-227.

16. Curl, A., Nelson, J. D., \& Anable, J. (2011). Does accessibility planning address what matters? A review of current practice and practitioner perspectives. Research in Transportation Business \& Management, 2, 3-11. https://doi.org/ 10.1016/.j.tbm.2011.07.001.

17. Ben-Akiva, M., \& Lerman, S. (1979). Disaggregate travel and mobility choice models and measures of accessibility. In D. A. Hensher, \& P. R. Stopher (Eds. ), Behavioural travel modelling, (pp. 654-679). London: Croom-Helm.

18. Dong, X., Ben-Akiva, M., Bowman, J., \& Walker, J. (2006). Moving from tripbased to activity-based measures of accessibility. Transportation Research Part A., 40(2), 163-180. https://doi.org/10.1016/j.tra.2005.05.002.

19. Kwan, M. (1998). Space-time and integral measures of individual accessibility: A comparative analysis using a point-based framework. Geographical Analysis, 30(3), 191-216.

20. Le Vine, S., Lee-Gosselin, M., Sivakumar, A., \& Polak, J. (2013). A new concept of accessibility to personal activities: Development of theory and application to an empirical study of mobility resource holdings. Journal of Transport Geography, 31, 1-10.

21. Cascetta, E., Cartenì, A., \& Montanino, M. (2013). A new measure of accessibility based on perceived opportunities. Procedia Social and Behavioral Sciences, 87, 117-132.

22. Crucitti, P., Latora, V., \& Porta, S. (2006). Centrality measures in spatial networks of urban streets. Physical Review E, 73(3), 036125.

23. Sandro, F., \& Uysal, M. (2006). Destination attractiveness based on supply and demand evaluation: Ananalytical framwork. Journal of Travel Research, 44, 418-430.

24. Kozak, M., \& Rimmington, M. (1999). Measuring tourist destination competitiveness: Conceptual considerations and empirical findings. International Journal of Hospitality Management, 18(3), 273-283.

25. Swarbrooke, J., \& Horner, S. (2007). Typologies of tourist behaviour and segmentation of the tourism market Consumer Behaviour in Tourism, (2nd ed. pp. 83-99). Oxford: Butterworth-Heinemann.

26. Bansal, H., \& Eiselt, H. A. (2004). Exploratory research of tourist motivations and planning. Tourism Management, 25(3), 387-396.

27. Urry, J. (2002). The tourist gaze, (2nd ed., ). London: Sage Publications Ltd.

28. Priskin, J. (2001). Assessment of natural resources for nature-based tourism: : The case of the central coast region of Western Australia. Tourism Management, 22(6), 637-648.

29. Brabyn, L., \& Skelly, C. (2002). Modeling population access to New Zealand public hospitals. International Journal of Health Geographics, 1, 1-3.

30. Dickinson, J. E., \& Robbins, D. (2007). Using the car in a fragile rural tourist destination: A social representations perspective. Journal of Transport Geography, 15(2), 116-126. 
31. Lew, A., \& McKercher, B. (2006). Modeling tourist movements: A local destination analysis. Annals of Tourism Research, 33(2), 403-423.

32. Israeli, Y., \& Mansfeld, Y. (2003). Transportation accessibility to and within tourist attractions in the old city of Jerusalem. Tourism Geographies, 5, 461-481.

33. Lawton, C. (2010). Gender, spatial abilities, and Wayfinding. In J. Chrisler, \& D. McCreary (Eds.), Handbook of gender research in psychology, (pp. 317341). New York: Springer.

34. Pyo, S. (2005). Knowledge map for tourist destinations--needs and implications. Tourism Management, 26(4), 583-594.

35. Mohd, F. A. K., \& Xia, J. (2010). Individual Differences in the Tourist Wayfinding Decision Making Process. In Paper presented at the 14th international symposium on spatial data handling, Hong Kong.

36. Xia, J., Packer, D., \& Dong, C. (2009). Individual differences and tourist wayfinding behaviours. In Paper presented at the 18th World IMACS / MODSIM Congress, Cairns.

37. Golledge, R., \& Stimson, R. (1997). Spatial behavior: A geographic perspective. London: The Guilford Press.

38. Hsu, C., Cai, L., \& Wong, K. (2007). A model of senior tourism motivations. Anecdotes from Beijing and Shanghai. Tourism Management, 28(5), 1262-1273.

39. Pearce, P., \& Lee, U. (2005). Developing the travel career approach to tourist motivation. Journal of Travel Research, 43(3), 226-237. https://doi.org/10. $1177 / 0047287504272020$.

40. Hinch, T., \& Higham, J. (2004). Sport tourism development. Australia: Channel View Publications.

41. Pearce, P. (2003). Anticipation. In J. Jafari (Ed.), Encyclopedia of tourism. New York: Taylor \& Francis.

42. Chhetri, P., \& Arrowsmith, C. (2008). GIS-based modelling of recreational potential of nature-based tourist destinations. Tourism Geographies, 10, $233-257$.

43. Kong, F., Yin, H., \& Nakagoshi, N. (2007). Using GIS and landscape metrics in the hedonic price modelling of the amenity value of urban green space: A case study in Jinan city, China. Landscape and Urban Planning, 79, 240-252.

44. Oh, K., \& Jeonge, S. (2007). Assessing the spatial distribution of urban parks using GIS. Landscape and Urban Planning, 82, 25-32.

45. Cascetta, E., \& Coppola, P. (2015). New high-speed rail lines and market competition: Short-term effects on services and demand in Italy. Transportation Research Record, 2475, 8-15. https://doi.org/10.3141/2475-02.

46. Cascetta, E. (2009a). Transportation system analysis: Models and applications. New York: Springer.

47. Papa, E., Coppola, P., Angiello, G., \& Carpentieri, G. (2017). The learning process of accessibility instrument developers: Testing the tools in planning practice. Transportation Research Part A, 104, 108-120. https://doi.org/10. 1016/j.tra.2017.03.010.

48. Spiekermann, K., \& Neubauer, J. (2002). European accessibility and peripherality: Concepts, models and indicators. Nordregio: Stockholm.

49. Dijkstra, E. W. (1959). A note on two problems in connexion with graphs. Numerische Mathematik, 1, 269-271.

50. Bellman, R. E. (1957). Dynamic Programming. Princeton: Princeton University Press Republished 2003: Dover.

51. Nguyen, S., \& Pallottino, S. (1989). Passenger assignment on a urban routes system: Determination of shortest hyperpaths. Operational Research, 39, 207-230.

52. EEA (2019). EMEP/EEA air pollutant emission inventory guidebook 2019 Technical guidance to prepare national emission inventories. In European Environmental Agency Report No. 13/2019.

53. Eggleston H.S., Gaudioso D., Gorissen N., Joumard R., Rijkeboer R. C (1993). CORINAIR working group on emission factors for calculating 1990 emissions from road traffic: volume1: Methodology and emission factors. Office for Official Publications of the European Communities. Bruxelles. https://hal. archives-ouvertes.fr/hal-01254189/document

54. Cascetta, E., \& Coppola, P. (2016). Assessment of schedule-based and frequency-based assignment models for strategic and operational planning of high-speed rail services. Transportation Research Part A, 84, 93-108. https://doi.org/10.1016/j.tra.2015.09.010.

55. Dupeyras, A., \& MacCallum, N. (2013). "Indicators for measuring competitiveness in tourism: A guidance document", OECD tourism papers, 2013/02. OECD Publishing. http://dx.doi.org/10.1787/5k47t9q2t923-en.

56. Cascetta, E., \& Coppola, P. (2014). High-speed rail (HSR) induced demand models. Procedia: Social and Behavioral Sciences, 111, 147-156.

\section{Publisher's Note}

Springer Nature remains neutral with regard to jurisdictional claims in published maps and institutional affiliations.

\section{Submit your manuscript to a SpringerOpen ${ }^{\circ}$ journal and benefit from:}

- Convenient online submission

- Rigorous peer review

- Open access: articles freely available online

- High visibility within the field

- Retaining the copyright to your article

Submit your next manuscript at $\boldsymbol{\nabla}$ springeropen.com 